\title{
Hydrostratigraphic Characterization in South-Eastern Coastal Aquifer of Bangladesh using Lithological Data and Step-drawdown Test
}

\author{
Mohammad Tofayal Ahmed ${ }^{1}$, Md Yeasir Hasan ${ }^{1}$, and Minhaj Uddin Monir ${ }^{1}$ \\ ${ }^{1}$ Jashore University of Science and Technology
}

April 28, 2020

\begin{abstract}
The hydrogeological investigation of south-eastern coastal aquifer of Bangladesh has been performed for the evaluation of well performance in the aquifer based on well logs and step-drawdown tests. The consequences from four single-well of stepdrawdown tests have conductd in two recent boreholes through Jacob and Rorabaugh's methods. From lithological data analysis it is observed that the aquifer of studied area is in Early Miocene age which consists of Upper and Middle Boka Bil formation. The values of step-drawdown test results have indicated well losses ranges between $17 \%$ and $19.8 \%$ and loss of aquifer on two well ranges between $82.6 \%$ and $80.2 \%$ which reflected higher efficiencies of two wells. The values of specific capacity have varied from two wells in totally $18.13 \mathrm{~m} 3 /$ day $/ \mathrm{m}$ to $23.79 \mathrm{~m} 3 /$ day $/ \mathrm{m}$, respectively whereas the values of well efficiency varied from $95.3 \%$ to $98.5 \%$ which indicate that the wells are properly developed and designed. The estimation of aquifer transmissivity ranges from 271.24 (m2/day) to 263.3 ( $\mathrm{m} 2 /$ day) and these values have evaluated the wells indicating the higher production with its water accessibility from the wells. Therefore, it is indicated the laminar flow of the aquifer/well-face (negligible part of turbulent flow). As a result, the water-bearing zone is effective for high amount of water production per day. The total approaches of litholog and pumping tests determine the effective application of the single-well on step-drawdown tests and it has identified the safe and sustainable well growth for the extraction of groundwater in future.
\end{abstract}

\section{Introduction}

The activities of urbanization, reclamation of the land and higher agricultural production have increased due to the incredible increase of human population (Sawant \& Shete, 2016). These activities have makes a higher demand for groundwater resources and it is increasing in higher to higher day by day (Al Tanjil, Ahmed, Akter, Biswas, \& Policy, 2019). Therefore, it has become a new challenge for the supplying of safe groundwater according to the demand of the population (Ahmed, Hasan, Khan, \& Hasan, 2019; Biswas et al., 2017). The authors (Hasan et al., 2016; Mahmood \& Environment, 2012) have indicated that the groundwater has flowed north to south in Bangladesh. This is happened because most of the rivers are connected in the north with the Bay of Bengal (Monir, Khan, Hossain, \& Hossain, 2011; Monir, Khan, Quamruzzaman, Kabir, \& Hossain, 2012) and elevation of these coastal areas is lower from the north to south (Sarker, Van Camp, Islam, Ahmed, \& Walraevens, 2018). The coastal area is connected with 19 districts of Bangladesh. Such flow of groundwater and elevation, salinity intrusion has been considered the main cause of potential water resources (Mahmuduzzaman, Ahmed, Nuruzzaman, \& Ahmed, 2014). The coastal regions is found higher sandy layers so irrigation activities have been considered a higher concern because of groundwater reported by Rahman, Rahman, and Majumder (2012). For this, the safe water zone is found in the higher depth of lithological distribution (Mahmood \& Environment, 2012). In the arid period (March to August), the water demand became acute in every year in Bangladesh because the water static table goes to low down (Mahmood \& Environment, 2012). Some authors (Rahman et al., 2012; Shammi et 
al., 2016; Shammi et al., 2017) have investigated that this higher increased stress of water demand has been emphasized the inhabitants collect water resources from the higher depth of lithological layers. Moreover, the safe water-bearing zone or saturated zone have been found in higher depth along the coastal district's areas of Bangladesh (Hasan et al., 2016).

The step-down test is considered as short pocess and moderately simple and cheaper than the other pumping tests because of this processes are regulated the highest rate of flow water in a well (Ophey et al., 2019). The proportion of abstraction on step-down test from the water level of the well is increased in different numbers of steps (minimum 3 times ) (Abdalla \& Moubark, 2018). Well-performance tests have been conducted to estimate the losses of energy in the aquifer and the pumping well which is developed during the extraction of groundwater. The procedures of pumping well consist of increasing discharge rates (Q) at a stepwise. Until the drawdown stabilized, it is measures every test temporary changes in water levels at every step (Kruseman, De Ridder, \& Verweij, 1970). Moreover, some researchers (Gahala, 2015; Louwyck, Vandenbohede, \& Lebbe, 2010) studied that the analytical process of step-drawdown test assists to identify the quantify aquifer mechanisms which evaluate the rate of flow into the well laminar/turbulent. The discharge rate $(\mathrm{Q})$ and time are proportional to the resistance of formation on the water-bearing zone. The well (non-linear) loss has considered as the parameter of difference between the immediately head of inside and the outside casing during pumping of an aquifer (F. J. P. b. J. S. Driscoll, St Paul, Minnesota, 1986). Jacob method (Jacob, 1947) has been applied for determining the pumping rate, step down tests and the specific pumping rate of an aquifer which has been considered as very easy and low expensive for calculation (Abdalla \& Moubark, 2018). According to Jacob's method, F. J. S. P. Driscoll, Minn (1986) has used the term of aquifer loss in laminar and turbulent term of well loss. Bierschenk (1963) also represented Jacob's method in a graphical interpretation for the determination of well loss and aquifer whereas Logan (1964) and Gabrysch (1968) have proposed the transmissivity estimation method from the loss coefficient of the aquifer. This transmissivity estimation method has been evaluated by various graphical interpretations from the coefficient on well loss. Singh (2002) has been applied this method for the determination of transmissivity (T), stepdown, specific recharge depends on Jacob method (Jacob, 1947). The single-well step-drawdown test and its performance of well criteria (coefficient of well loss, the efficiency of well) provides the estimation of highest yield (optimal pumping propotion) under varying conditions of the water-level (Guttman, Negev, \& Rubin, 2017).

The lithology of subsurface deposits, saturation of (aquifer) thickness, groundwater depth, hydraulic properties of the aquifer is controlled the hydrogeologic characteristics and potential of grundwater resouces in a area. In the previous study (M. T. Ahmed et al., 2019), it has investigated the distribution of groundwater quality and its valuation on Shagordari but there is no indicator of lithological distribution and aquifer characteristics. Another study (M. Ahmed et al., 2019) has indicated only the hydrogeological condition of Jessore but there is no evaluation pumping rate or well performance according to hydrochemistry. Moreover, several authors (Jahan et al., 2007; Tanvir Rahman, Rahman, Majumder, \& Technology, 2012) have also identified the depositional environment of the aquifer by using the gamma-ray well log data. However, there is no identification of well of recharge. As the water level has been being decreased day by day so static water level and the recharge rate condition of the water should be needed to water resources safety. Moreover, it has evaluated by the authors (Abdalla \& Moubark, 2018; Louwyck et al., 2010) that step drawdown (aquifer) pumping and performance tests have been considered as the main process to determine the sufficient and accurate assumption of groundwater resources in any aquifer.

Therefore, this study evaluated the performance of well criteria, steps drawdown and pumping tests of the investigation area. Hence, the main objectives of this investigation area have indicated that the identification of the safe zone according to various pumping rates, step down test and estimation of well performance with its aquifer characterization by the estimation of well loss and well efficiency, the specific capacity of well and an optimal pumping rate of various water-level conditions. This study also evaluated the lithologic characteristics of the aquifer, water-bearing zone from the logging data and levels of aquifer zone.

\section{Study area}




\subsection{Location}

The study area (Wellpoint) is situated beside the Bay of Bengal. The longitude and lattitude of the studied area are $92^{\circ} 03^{\prime}$ to $92^{\circ} 12^{\prime}$ and $21^{\circ} 08^{\prime}$ to $21^{\circ} 21^{\prime}$, respectively. It is situated on the last corner of Ukhia Upazila, Cox's Bazar (Fig. 1). The humidity is very high in this area. Every year (July-September) different disasters attacked this area. Tidal saline water from the sea is another problem in the studied area. The temperature of seasonal variation in winter to summer is considered around 12-42 degrees. The rainy season occurs stay in high time because of the seasonal monsoon every year. Sometimes heavy rainfall is formed seasonal characterization bay of Bengal. In summer, the temperatures are also high (over 42 degrees). The borehole areas was selected to reach the maximum number of water supply without any risk of flooded away during the rainy season and the land was not stored any stagnant water. In the north-western zone, this wellpoint area is one of the most readily available fo the water supply in these areas for agriculture. As this area is the coastal part of Bangladesh therefore, safe groundwater evaluation is the urgent need of this area.

\subsection{Geological setting}

The studied area is located on the side of the youngest structural division in the western Indo-Burman Range of the folded flank (Kresic, 2006; Nahin, Basak, Alam, \& Environment, 2019). The elevation of this area is very low from the other areas of Bangladesh. The majority of the land is found in hilly reason. In the east boundary which is covered in low hilly ranges (100m elevations) and west side is covered by Bay of Bengal. Bakkhali estuary and Maheshkhali channel are found in the north and south. The landform types of this area are divided into two categories flooded and coastal plain. The beach plain unit has been consisted of dunes, tidal creeks and beach. The floodplain unit has been consisted of the Tertiary hills between the hilly reason. The flat surface mainly consisted of sandy clay and sand size is larger in continuously higher on the depth.

\section{Methodology}

This study was conducted with Asia Arsenic Network (AAN) in Ukhia Upazila, Cox's Bazar, Bangladesh. This work was run under the technical support of DPHE, Bangladesh. AAN was installed two pumping well in the study area. The field survey was provided water static table and higher depths of water level, elevations of ground, lithological and hydro chemical data of step-drawdown well tests the well No 2 and 4. These two wells was installed for the improvement of existing safe water supply systems. Identification of safe water, actual well construction, regulation of pumping rate, step drawdown, static water table, lithologic and geophysical setting were monitored during and before the drilling activities.

\subsection{Manual preparation of a well}

\subsubsection{Drilling}

For the drilling construction of wells, 30" (Well No. 4) and 22" (Well No. 2) temporary casing up to 3m was installed. Soil sample for bore log preparation was collected from each $3 \mathrm{~m}$ interval, all drilling pipes were measured, marked with red tape as an indication of soil sample collection time. These wells cutting were started on December 07, 2019 and October 20, 2019, respectively. The used drills were 12" cutters and drilling procedure was conducted by Kazal Enterprise. $35 \mathrm{KW}$ generator was used for power supply, $7.5 \mathrm{HP}$ pump for circulating of water, semi-mechanical rotary drilling machine with 10-ton lifting capacity and 2.5inch dia drilling pipes were used. The used drilling fluids were local mud and bentonite. All collected soil samples were properly washed and stored after marking the depth. The bore log format was observed by AAN hydrogeologist and technical supervisor by checking of collecting soil samples. For Well No. 2, 1st cutting reached $237.80 \mathrm{~m}$ and found continuous fine to medium sand layer from $189.02 \mathrm{~m}-237.80 \mathrm{~m}$ whereas the Well No. 4, 1st cutting reached $243.90 \mathrm{~m}$ and found the continuous medium to fine sand layer from $204.27 \mathrm{~m}-$ $243.90 \mathrm{~m}$. The water-bearing zone identification or simulation was developed by MATLAB (version 16) and it is modified by Adobe Photoshop (version Ps 17).

\subsubsection{Borehole Geophysical Logging Operation}


In this study, drilled up to $244 \mathrm{~m}$ (Well No. 4) and $235 \mathrm{~m}$ (Well No. 2) depth and at every $1.5 \mathrm{~m}$ interval sediment samples were collected up to drill depth. After completion, drilling Borehole Geophysical Logging carried out in this borehole. Short (16") normal, long (64") normal resistivity (ohm-m), single-point resistance and spontaneous potential (SP-mv) logging was been carried out. The logging data was collected at the interval up to $244 \mathrm{~m}$ and $235 \mathrm{~m}$ from the topsoil.

\subsubsection{Interpretation of Geophysical Logging Data}

The self-potential $(\mathrm{mV})$ and resistivity $(\mathrm{ohm}-\mathrm{m})$ data were plotted with the recorded lithology in the log of the two-borehole correlation. In general, the long normal resistivity data was found indicative of the formation resistivity of the undisturbed and distributed zone while short normal resistivity data were influenced by borehole face and mud fluid. The SP along with resistivity data was found indicative of separation of layer boundary as changes by lithology or formation of the aquifer.

\subsection{Evaluation of pumping unit characterization}

\subsubsection{Step-drawdown test}

Jacob (1947) has formulated the step-drawdown test and Rorabaugh (1953) has modified it. These studies have been assumed as a homogenous and confined aquifer. It is anisotropic with the infinite areal extent and the pumping well which has fully penetrated the aquifer. The thickness of the aquifer, static water table aquifers with small drawdown and its solution has presented by Jacob (1947) and Rorabaugh (1953). The total process has been accepted by F. J. P. b. J. S. Driscoll, St Paul, Minnesota (1986). The whole methodology of pumping test and its analysis procedure has developed by Kresic (2006). After well construction, the step-drawdown tests have conducted immediately. To identify the well efficiency and aquifer transmissivity, the coefficients of $\mathrm{B}$ and $\mathrm{C}$ have been required to determine. On the basis of graphical method of Rorabaugh (1953) the step-test data have been evaluated. Actually, it is the straight-line method of adaptation of Jacob (1947). The total depths of Well No. 2 and Well No. 4 have 235m and 244m, respectively. Each well-pumping test has been included in 4 steps. The satellite maps have made also depend on other geologic and hydrogeological data.

\subsubsection{Pumping rate}

Jacob (1947) mainly had proposed the relation of pumping rate and the total components of the drawdown of a pumping well by the equations.

$S_{w}=\left(B Q+C Q^{2}\right)$

Where,

$\mathrm{S}_{\mathrm{w}}=$ whole drawdown $(\mathrm{L} ; \mathrm{m})$

$\mathrm{Q}=$ pumping or discharge value $\left(\mathrm{L}^{3} / \mathrm{T} ; \mathrm{m}^{3} /\right.$ day $)$

$\mathrm{B}=$ loss coefficient of aquifer or formation $\left(\mathrm{T} / \mathrm{L}^{2}\right.$; day $\left./ \mathrm{m}^{2}\right)$

$\mathrm{BQ}=$ component drawdown owing to the aquifer or formation loss with the flow of laminar in the aquifer $(\mathrm{L} ; \mathrm{m})$

$\mathrm{C}=$ coefficient well loss $\left(\mathrm{T}^{2} / \mathrm{L}^{5} ;\right.$ day $\left.^{2} / \mathrm{m}^{5}\right)$

$\mathrm{CQ}^{2}=$ drawdown component because of well loss or flow of turbulent in the early approach of the well through the gravel pack and/or screen (L; m)

Rorabaugh has modified the Equation (1) and it has been substituted "n" as a variable of the exponent of the equation on the turbulent flow that has determined empirically as:

$S_{w}=\left(B Q+C Q^{n}\right)(2)$ 
The parameter " $\mathrm{n}$ " has assumed between the ranges of values of 1.5 and 3.5 , on the basis of $\mathrm{Q}$ value. But Kawecki (1995) has supported and it is widely accepted $(n=2)$ by Kresic (2006) that is proposed by Jacob (1947).

\subsubsection{Specific drawdown}

To convert the Equation (1) of the form on linear, it has been divided both sides by yield of Q:

$$
\frac{S_{W}}{Q}=(B+C Q)
$$

The specific drawdown has represented by $\mathrm{Sw} / \mathrm{Q}$ and it has plotted vs $\mathrm{Q}$. Then, the points have retreated through the line-of-best fit. The well loss has considered the equality of the slope to the line-of-best fit on the turbulent flow coefficient. The aquifer loss is considered as the equal to the line of intercept with y-axis of loss coefficients of laminar flow in which $\mathrm{Q}=0$.

\subsubsection{Specific capacity}

The quantity of water is considered as the specific capacity $(\mathrm{Sc})$ and it is calculated by per unit of drawdown in the well. The yield per unit drawdown has represented simply by it. A stable pumping level has marked it. When recharge has balanced to the discharge, it has established. The parameter of calculation has followed in such equations:

$S_{c}=\left(\frac{Q}{S_{w}}\right)$

Where,

$\mathrm{Sc}=$ specific capacity $\left(\mathrm{L}^{3} / \mathrm{T}^{-1} / \mathrm{L} ; \mathrm{m}^{3} /\right.$ day $\left./ \mathrm{m}\right)$

$\mathrm{Q}=$ discharge or pumping rate $\left(\mathrm{L}^{3} / \mathrm{T} ; \mathrm{m}^{3} /\right.$ day $)$

$\mathrm{S}_{\mathrm{w}}=$ total or steady drawdown in the pumping well $(\mathrm{L} ; \mathrm{m})$

The data of specific capacity has frequently used so that it frequently is estimated the transmissivity of aquifer transmissivity in place (Fetter, 2018; Rajmohan \& Elango, 2004; Razack \& Huntley, 1991). Moreover, it is more expensive to regulate the total performance of aquifer tests. Although the data and equations have applied to identify the transmissivity with its inherent limitations and errors as potential (Gahala, 2015). Partial penetration of well, well loss and hydrogeological boundaries, values of transmissibility that have been calculated from specific capacity data by underestimate of actual values effect on the pumping tests unfavorably (Misstear \& Beeson, 2000).

\subsubsection{Transmissibility values}

Transmissibility values have measured both characterization of the aquifer and well effectiveness. The empirical relation has derived by Razack and Huntley and also assumed the values of low well loss, a homogenous and porous aquifer of isotropic. The aquifer transmissivity is estimated through the calculation of specific capacity. For porous aquifers in alluvial, Razack and Huntley (1991) have been provided the empirical relation with simple means of attaining the estimation on the initial stage in followed ways:

$\mathrm{T}=\left[33.6 \times\left(\frac{Q}{S_{W}}\right)^{.67}\right](5)$

Where,

$\mathrm{T}=$ transmissivity $\left(\mathrm{L}^{2} / \mathrm{T} ; \mathrm{m}^{2} / \mathrm{min}\right)$

$\mathrm{Q}=$ discharge or pumping rate $\left(\mathrm{L}^{3} / \mathrm{T} ; \mathrm{m}^{3} / \mathrm{min}\right)$

$\mathrm{S}_{\mathrm{w}}=$ total or steady drawdown in the pumping well $(\mathrm{L} ; \mathrm{m})$.

\subsubsection{Well efficiency}


Well efficiency $\left(E_{\mathrm{w}}\right)$ is considered as the ratio of aquifer head loss BQ (just outside the casing of the theoretical drawdown) whereas the total drawdown has been measured as Sw inside the well of pumping. However, it is the ratio of head loss of the laminar flow to the total of the laminar and turbulent flow of head loss. On the basis of Rorabaugh (1953), it has calculated on as follows:

$\mathrm{E}_{\mathrm{W}}=\left[100 \times\left(\frac{\frac{Q}{S_{W}}}{\frac{Q}{\mathrm{BQ}}}\right)\right](6)$

Rewritten the equation (6), it can be formulated in following ways:

$\mathrm{E}_{\mathrm{W}}=\left[\left(\frac{\mathrm{BQ}}{S_{W}}\right) \times 100\right](7)$

Values of $\mathrm{E}_{\mathrm{W}}$ has been considered acceptable as $70 \%$ acceptable by Kresic (2006) and it has indicated in a designed properly and well developed. When $\mathrm{E}_{\mathrm{W}}=100 \%$, the well loss term is identified the values as $\mathrm{CQ}^{2}$ is zero. Several factors have affected the efficiency of well, the most significant being the drilling process, screen design of the screen, size of the gravel pack and development system. When screen length is insufficient, openings of the screen are too short, incomplete penetration of well in the aquifer, insufficient development of well are the main cause of low well efficiency. The aquifer pore spaces have plugged by the drilling fluid and silty and fine materials infiltration. The factor of well development has been indicated by Bierschenk (1963), the well loss to formation loss ratio is 100. On the basis of Bierschenk (1963) classification, when the development factors are $<0.1$, it has represented the reflect "very effective" development, when the values are indicated the ranges 0.1 to 0.5 which means the development is "effective", when the values range is 0.5 to 1.0, it has indicated the development "fairly effective" and when the values range is $>1.0$, it is indicated the development "poorly effective". The equation of the development factors on total ranges have calculated as follow:

$\left[\left(\frac{C}{B}\right) \times 100\right](8)$

\section{Results and Discussion}

\subsection{Evaluations of qualitative/quantitative description of lithology}

Lithologic data has collected during drilling and step-down or pumping test. Data on well depths and locations, static water levels have also collected during field observations and geophysical logging. The waterbearing zone has been shown with the resistivity and self-potential log by simulation for higher accuracy of this research.

\subsubsection{Lithological characterization of well}

Data has collected during the activities of drilling from logging of geophysical interpretation on the two test wells (Table 1 and Fig. 2) and the drilling has suspended after 235m (Well No. 2) and 244m (Well No. 4) from the static water level. The lithological results from well logging in layer by layer have shown in Table 1. The correlation between the two log's interpretations has also shown in Fig. 2(a). The description of litho-log and well design has described on (Fig. 2(a) and Fig. 2 (b)). From Table 1 the Well No. 2 has found 16 layers on $235 \mathrm{~m}$ depth whereas the Well No. 4 has been found on 10 layers on $244 \mathrm{~m}$ depth. The resistivity $\log$ value is higher in the clay layers. Again, this $\log$ value is also higher on the sand layers but not higher the clay layers. These processes also the same in the self-potential $\log$ (sand value $<$ clay value). From the Well No. 2, it has identified that 3rd, 5th, 7th, 9th, and 13th layers are mainly found as clay zone. These layers work as the seal of the sandstone. 1st, 4th, 14th, and 18th are the zone of fine to medium sand layers and $16^{\text {th }}, 12^{\text {th }}$ and $4^{\text {th }}$ are the medium to massive sandstone layers. The $10^{\text {th }}$ and $15^{\text {th }}$ are called the layers of fine sand. The $\left(14^{\text {th }}-16^{\text {th }}\right)$ layers are found as the water-bearing zone of the layers $(170-235) \mathrm{m}$ of the Well No. 2 and these layers are found as high permeable fine and medium sand. Moreover, the lithology of the Well No. 4 (Table 1) and (Fig. 2(a) and Fig. 2(b)), there is found 10 layers. The $5^{\text {th }}, 7^{\text {th }}$, and $9^{\text {th }}$ are the clay zone which is low permeable and but higher resistivity and SP log values. It has interpreted that $1^{\text {st }}$ and $3^{\text {rd }}$ layers fine with very fine sand, $2^{\text {nd }}$ is found fine to medium sand. In addition, the layers $4^{\text {th }}, 6^{\text {th }}$ and $8^{\text {th }}$ are found medium to fine sand. The high layers of fine to medium sand are the 10 layers where the 
water-bearing zone is located (Fig. 2(a) and Fig. 2(c)). The main aquifer zone has been found from the lithologic layers $10^{\text {th }}$ (Well No. 4) and $\left(14^{\text {th }}-16^{\text {th }}\right)$ (Well No. 2) and the zone of permeable fine to medium sandstone zone. Depth of the aquifer zone of two lithologic correlation layers (Well No. 4) (187m-244m) and (Well No. 2) (170m-135m) (Fig. 3(b) and Fig. 3(c)).

\subsubsection{Stratigraphic formation of the aquifer}

The Bengal Basin of the eastern folded belt portion has exposed the molasses sediments of geosynclinals on the age of Neocene that has consisted of varying proportions on the shale, mudstone, siltstone and sandstone. This lithological succession has been subdivided into Surma (Bhuban and Bokabil), Tipam and Dupi Tila Groups according to the classification reported by Alam (1989). Most of the portion of Bangladesh has covered sedimentary deposits of Tertiary and Quaternary that thicken larger portions to the south. Cox's Bazar, Ukhia Upazila zone has found in the same category (Curray, 1991). The strata of Cox's Bazar has considered as the last part of deltaic Bangladesh. Most of the part in the lithology on the study area has covered by sandstone and clay layers (Table 2). The southern part of Cox's Bazar city (Ukhia Upazila) has consisted of the recent sedimentary deposit of Bokabil Formation. However, majority of this area is covered by Tipam formation. The 2nd lithological zone of aquifer has formed by the Girujan Clay in the Middle Miocene age, but it is a very narrow area of the subsurface (Fig. 2). The $3^{\text {rd }}$ lithological formation of aquifer has covered Tipam Sandstone formation that it has been formed a larger portion and it's two side has been sealed by the clay layers (Fig. 2). The formation of Tipam Sandstone has unconformable underlined by formation of Boka Bil in a gradual dip low sequence upper the $4^{\text {th }}$ aquifer zone. Here the formation of Boka Bil is considered as the oldest portion of lithological characteristics of the aquifer (Zakaria, Islam, Rahman, \& Vol, 2015). From the lithological field observation and data measurement and (Fig. 2(a)), it has been indicated that thickness has expanded of the upper sandstone, Dupi Tila (DT) formation from $20 \mathrm{~m}$ to140m (sandstone), the formation of Girujan Clay has expanded from 140m to152m (clay zone). Moreover, the formation of Tipam Sandstone is expanded from $152 \mathrm{~m}$ to about $183 \mathrm{~m}$ (Sandstone with clay). The oldest exposed formation thickness of Upper Boka Bil (siltstone with clay or shale) and Middle Boka Bill (sandstone; fine to medium) has expanded $183 \mathrm{~m}$ to $187 \mathrm{~m}$ and 187 to $244 \mathrm{~m}$, respectively. The last zone (sandstone; medium sandstone and massive) which is sealed by upper clay layers and it has considered as the water-bearing zone or higher permeable zone.

\subsubsection{Characteristics of the water-bearing zone}

There are found a vast difference between hydrogeological conditions in other areas from the coastal region of Bangladesh. The main aquifer transmissivity on coastal aquifer have found the ranges from $250 \mathrm{~m}^{2} /$ day to $10000 \mathrm{~m}^{2}$ /day with the average value of $1000 \mathrm{~m}^{2} /$ day. Generally, the aquifer storage capacity has increased with depth with the grain size of aquifer materials increase. It has indicated by the authors (Bakhtine \& Industry, 1966; Zakaria et al., 2015), the thickness of water-bearing in the different depth of the study area and actual hydrogeology has considered as complex in nature. From Fig. 2(a), hydro stratigraphic (Table 2) sections has been divided into five lithologic part with the correlation of two wells: (a) sandstone and topsoil, (b) clay stone zone, (c) sandstone with clay (d) shale (siltstone and clay) and last (e) sandstone. The main water aquifer zone has found in the Early Miocene age and the formation of Middle Boka Bil (Fig. $3(\mathrm{~A})$ ). The lithologic responses of the resistivity $\log (35.6-42.7)$ oh-m. The cross of the actual water-bearing zone section of the two different wells has been divided depend on their hydro stratigraphic unit. According to the water-bearing condition, the aquifer geometry of the lithologic characteristics has divided into 4 parts on the top to bottom Fig. 4 (A): (1) water table (2) aquiclude (3) aquitard (4) aquifer. From the lithological analysis of individual logs (resistivity and SP $\log$ ) of the cross-section has been indicated the aquifer on the Middle Boka Bil (Early Miocene age) on $184 \mathrm{~m}$ to $244 \mathrm{~m}$ depth and it has considered the main aquifer zone of safe groundwater.

\subsection{Pump installation characteristics}

\subsubsection{Production well design and development}

The design of proper efficiency of the two well production has been required to yield maximized, proper the 
construction of selecting the materials, casing diameter of the two well and depth, and the interval screened. Lower maintenance and operation costs are the main factors of properly-designed of wells (Naggar, 2005). The selected diameter of the well $160 \mathrm{~mm}$ and it has provided the percentage desired of the slotted (open) area in the screen (14\% to 19\%) and it is ensured the pumped groundwater velocity near the screen for minimizing the drawdown and losses of well (Fig. 4(e)) and (Fig. 3(c)). It also prevents the migration of sand and clay- or silt-sized particles because of using the $150 \mathrm{~mm}$ piping (Smith, 1966). The grain size of the penetrated beds and selected slot sizes has depended on the appropriate screen slot size depends. These particles are prevented at least $90 \%$ of the aquifer substances from entering the well at the time of pumping. The filter or artificial gravel pack (clean, uniform-sized, well-rounded grains) must be used around the casing and screen of the well (Naggar, 2005). Then it is sealed to the above so that clogging the screen can prevent the fine material. The design of well screen has affected by well productivity and efficiency (Zakaria et al., 2015). The features of design have been included screen diameter, length, slot size, and material. The amount of water entering the pipes maximized by the proper screen designs and minimized by entering sediments entering the screen (Naggar, 2005). The screen is placed where permeable layers has been found. In the two well $4^{\text {th }}$ aquifer has considered as the confined aquifer and high thickness and homogeneous well of the water-bearing zone. The main process of pipe installation and water production has shown in Fig. 4(a-f) and Fig. 5.

In this study, it is found that design has been included $200 \mathrm{~mm}$ dia, $200 \mathrm{x} 150 \mathrm{~mm}$ dia reducing socket, $150 \mathrm{~mm}$ blind pipe, $150 \mathrm{~mm}$ strainer which is 30 slot and $150 \mathrm{~mm}$ bail plug. The total fixture length is 226.37 meters of the well $2^{\text {nd }}$ whereas the total fixture length is $232.45 \mathrm{~m}$ well $4^{\text {th }}$. For well No. 4 , at first bail plug jointed by using glue and screw with $150 \mathrm{~mm}$ class E blind pipes $6 \mathrm{~m}$ and lower to borehole than strainer has been started from 225.79 to $197.56 \mathrm{~m}$, in total 10 pieces of $150 \mathrm{~mm}$ dia class E pipes with the length of $3 \mathrm{~m}$. Total strainer length of $28.20 \mathrm{~m}$. Blind pipes as well casing started from 197.56 to $57.98 \mathrm{~m}$, in total 24 pieces of $150 \mathrm{~mm}$ dia class E pipes (Fig. 4(f)) with the length of $6 \mathrm{~m}$. For well No. 2, at first bail plug jointed by using glue and screw with $150 \mathrm{~mm}$ class E blind pipes 6 meters and lower to borehole than strainer started from 220 to 191.77 meters, in total 10 pieces of $150 \mathrm{~mm}$ (Fig. 4(b)) dia class E pipes with the length of 3m with 30 slots. Total strainer length is $28.20 \mathrm{~m}$. Blind pipes as well casing started from 191.77 to $75.32 \mathrm{~m}$, in total 20 pieces of $150 \mathrm{~mm}$ dia class $\mathrm{E}$ pipes with the length of $6 \mathrm{~m}$. The development of two well has enhanced aquifer material's permeability by using the chemical calculation and gravel checking. This calculation increases the production of well yield and efficiency (Naggar, 2005; Zakaria et al., 2015). When slotted openings are larger, the water velocity and frictional resistance are smaller. Drilling methods and features of the surroundings beds (aquifer materials) has been monitored by the development techniques of well.

\subsubsection{Flow of groundwater and water table of the study area}

Fig. 1 has shown the study area which is situated on the side of the Bay of Bangla. It is indicated by different authors (Alam, 1989; Curray, 1991; Zakaria et al., 2015) that the water level is lower in the coastal areas of Bangladesh. The water table has found in a higher depth of $28.5 \mathrm{~m}$ in the study area (Table 1). The water level of Well No. 4 has found moderate depth, but the water level of the Well No. 2 has been found in higher depth. The groundwater flow of Bangladesh has been found to the north to south. The safe water-bearing zone has found in higher depth for the topographic variation surroundings of the study area (Fig. 3(A)) and (Fig. 2(a) and Fig. 2(c)).

\subsubsection{Calculation of well loss and aquifer loss coefficient}

The average loss coefficients aquifer has been calculated for the four steps in the respectively for Well No. 4 and Well No. $241.45 \mathrm{~min} / \mathrm{m}^{2}, 41.64 \mathrm{~min} / \mathrm{m}^{2}$, whereas the average well loss coefficients $\mathrm{C}$ has been also calculated on four-step for Well No. 4 and Well No. $242.85 \mathrm{~min} / \mathrm{m}^{5}$ and $50 \mathrm{~min} / \mathrm{m}^{5}$, respectively (Table 3 and Fig. 6). On the basis of Walton's classification (Nahin et al., 2019; Walton, 1962) of well loss coefficient and the values between the coefficient and conditions of wells, the two wells have tested for this investigation area that is properly developed and designed. However, the percentages of formation loss have found on average $98.95 \%$ (Well No. 4) and 99.42 (Well No. 2), respectively (Table 3). It has indicated that the larger distance of the pump intake between the screens has increased the entrance of velocity and hence the 
water to the well has been indicated its frictional resistance. It has evaluated by results that all of the wells exhibited higher loss formation percentages compared between the well loss percentages of the average well efficiencies (Table 3). This has been explained by the facts of the two wells that make the aquifer streaming of flow in the aquifer and it is predominantly laminar of the turbulent flow on the well efficiencies between the well face and the aquifer area. The studied results also show that when the well losses lower with well of aquifer efficiencies, the higher percentage of reduction has found in the specific capacity that is generally low; conversely, wells showing higher substances of step drawdown because of the well losses exhibits relatively higher.

\subsubsection{The calculation of specific capacity and aquifer transmissivity}

From Table 3 it has apparent that Q/Sw max is considered as the specific capacity of average the step-down test for the two wells, and that the specific capacity is proportional to increasing well loss inversely. The calculation of specific capacity has found $21.81 \mathrm{~m}^{3} /$ day $/ \mathrm{m}$ and $20.56 \mathrm{~m}^{3} /$ day $/ \mathrm{m}$ at wells Well No. 4 and Well No. 2, respectively. These values have reflected the lower pumping water levels and, hence it makes the costs of pumping also lower.

The values of transmissivity have calculated from the specific-capacity data $271.24\left(\mathrm{~m}^{2} /\right.$ day $)$ and $263.3\left(\mathrm{~m}^{2} /\right.$ day) for Well No. 4 and Well No. 2, respectively (Table 3). These values have reflected very good productivity of aquifer (higher yields) and high amount of groundwater accessibility by the pumping wells. There are found smaller differences of transmissivity between two wells and these wells are found in the same sedimentary facies in different thicknesses and same water-bearing bed. It has mentioned that values transmissivity has calculated by specific capacity data and it has been evaluated by the actual (true) values. Therefore, partially penetrating production well, the quantity of well loss and the presence of hydro-geologic boundaries has affected.

\subsubsection{Well efficiency characterization}

The average efficiencies have been found in the Well No. 4 is $95.26 \%$ and in the Well No. 2 it is $93.25 \%$. The higher efficiency of the well reduces the costs of pumping. According to Kresic (2006), the values of $>70 \%$ have been accepted for the good production of water. This rate of efficiency indicates the proper designed and developed wells. The development factor of Well No. 4 is 0.0005 and Well No. 4 is 0.00725 . On the basis of Bierschenk's classification (Bierschenk, 1963), the factor values of these wells are $<0.1$ which indicated that the studied wells are "very effective".

\section{Conclusions}

The investigation of the hydrogeologic characterization has been included two single-well pumping tests design. This also indicates the formation (Early Miocene age and Boka Bil) and the safe water zone by the lithologic interpretation. The pumping test has also indicated the performance of well criteria and aquifer characteristics. The well performance has evaluated by applying the graphical analysis of the Jacob methods. It has estimated the formation and well loss of drawdown. The ideal design of the two wells have been developed for groundwater exploration by choosing the accurate model of the screen as well as casing of a well. The pumping test results have also shown the aquifer flow is mainly laminar, but the turbulent flow is highly negligible because the well loss is much lower than the formation losses. The test of two wells has been properly developed for optimizing the greater effectiveness by removing fine materials from the face of two well. The pumping test has helped to develop transmission as much of the aquifer's wideness as possible. Higher specific capacity values and transmissivity values (evaluate from test of specific capacity data) has indicated that the aquifer has been considered as higher productivity of water. The total efficiency of the two wells (from 95.3\% to 98.5\%) and these indicated the proper design and higher effective well for water exploration.

\section{Acknowledgments}

We thank ETAPA-EP and the Ecuadorian Ministry of Environment for 
providing research permits to conduct this study. Thanks are due to Juan Pesantez, Dario Zhina, Diego Pomaquiza, Mishel Palacios, and all the graduate and undergraduate students who supported the field sampling collection. Gratitude is expressed to Rolando Celleri and Jeffrey McDonnell for providing critical revisions on earlier versions of this manuscript. This manuscript is an outcome of the Doctoral Program in Water Resources of the Universidad de Cuenca. This research was funded by SENESCYT and the Direccion de Investigacion de la Universidad de Cuenca (DIUC) through the project "Desarrollo de indicadores hidrologicos funcionales para la evaluacion del impacto de

The authors would like to thank the Environmental Laboratory, Asia Arsenic Network, Arsenic Center, Beanpole Road, Krishnobati, Pulerhat, Jashore -7400, Bangladesh for providing lab facilities.

\section{Data Availability Statement}

The investigated data of this study are available in the Table 1 and stratigraphic data (https://doi.org/10.1016/00310182(89)90159-4 and DOI: 10.9790/0990-03632128) that supports the findings of this study are available in the Table 2 of this article.

\section{ORCID}

Mohammad Tofayal Ahmed (https://orcid.org/0000-0003-4093-7845)

Minhaj Uddin Monir (http://orcid.org/0000-0002-3968-541X)

\section{References}

Abdalla, F., \& Moubark, K. J. J. o. A. E. S. (2018). Assessment of well performance criteria and aquifer characteristics using step-drawdown tests and hydrogeochemical data, west of Qena area, Egypt. 138, 336347.

Ahmed, M., Woobaidullah, A., Quamruzzaman, C., Hossain, R., Islam, M. S., \& Mehnaz, N. (2019). The Evaluation of Hydrogeological Condition: A Case Study on Jessore Sadar, Bangladesh.

Ahmed, M. T., Hasan, M. Y., Khan, A. S., \& Hasan, M. (2019). Valuation of Irrigation Water at Shagordari, Jashore, Bangladesh. International Research Journal of Engineering and Technology, 6, 1050-1057.

Al Tanjil, H., Ahmed, M. T., Akter, S., Biswas, P. K. J. I. J. o. E. P., \& Policy. (2019). Water Quality Assessment in Maddhapara Granite Mine, Bangladesh. 7(2), 39.

Alam, M. J. P., Palaeoclimatology, Palaeoecology. (1989). Geology and depositional history of Cenozoic sediments of the Bengal Basin of Bangladesh. 69, 125-139.

Bakhtine, M. J. S., \& Industry. (1966). Major tectonic features in Pakistan, part II, Eastern Province. 4(2), 89-100.

Bierschenk, W. H. (1963). Determining well efficiency by multiple step-drawdown tests: International Association of Scientific Hydrology.

Biswas, P., Uddin, N., Alam, S., Sultana, S., Ahmed, M., \& Sakib, T. J. A. J. o. W. R. (2017). Evaluation of heavy metal pollution indices in irrigation and drinking water systems of Barapukuria coal mine area, Bangladesh. 5(5), 146-151.

Curray, J. R. J. J. o. A. o. E. G. (1991). Geological history of the Bengal geosyncline. 12(4), 209-219. 
Driscoll, F. J. P. b. J. S., St Paul, Minnesota. (1986). Groundwater and wells second edition. 55112.

Driscoll, F. J. S. P., Minn. (1986). Groundwater and wells (2d ed): Johnson Division.

Fetter, C. W. (2018). Applied hydrogeology: Waveland Press.

Gabrysch, R. K. J. G. (1968). The relationship between specific capacity and aquifer transmissibility in the Houston area, Texas. 6(4), 9-14.

Gahala, A. M. (2015). Evaluation of Aquifer Interconnection from Aquifer Characteristics Computed by Using Specific Capacity Data within the Vicinity of the Tremont Barrel Fill Site, Clark County, Ohio: US Department of the Interior, Geological Survey.

Guttman, J., Negev, I., \& Rubin, G. J. W. (2017). Design and testing of recharge wells in a coastal aquifer: summary of field scale pilot tests. 9(1), 53.

Hasan, M. R., Keramat, M., Shahid, S., Yasmin, R., Mohsenipour, M., Sattar, G. S. J. G., \& Engineering, G. (2016). Evaluation of Subsurface Lithologic Units for Groundwater Exploration in the Barind Tract of Bangladesh. 34(5), 1395-1411.

Jacob, C. E. (1947). Drawdown Test to Determine the Effective Radius of an Artesian Well, Trans. Paper presented at the ASCE.

Jahan, C. S., Islam, M. A., Mazumder, Q. H., Asaduzzaman, M., Islam, M. M., Islam, M. O., \& Sultana, A. J. J.-G. S. O. I. (2007). Evaluation of depositional environment and aquifer condition in Barind area, Bangladesh using Gamma Ray Well Log Data. 70(6), 1070.

Kawecki, M. J. G. (1995). Meaningful interpretation of step-drawdown tests. 33(1), 23-32.

Kresic, N. (2006). Hydrogeology and groundwater modeling: CRC press.

Kruseman, G. P., De Ridder, N. A., \& Verweij, J. M. (1970). Analysis and evaluation of pumping test data (Vol. 11): International institute for land reclamation and improvement The Netherlands.

Logan, J. J. G. (1964). Estimating transmissibility from routine production tests of water wells. 2(1), 35-37.

Louwyck, A., Vandenbohede, A., \& Lebbe, L. J. J. o. h. (2010). Numerical analysis of step-drawdown tests: Parameter identification and uncertainty. 380(1-2), 165-179.

Mahmood, S. A. I. J. J. o. E., \& Environment, t. N. (2012). Impact of climate change in Bangladesh: The role of public administration and government's integrity. 4(8), 223-240.

Mahmuduzzaman, M., Ahmed, Z. U., Nuruzzaman, A., \& Ahmed, F. R. S. (2014). Causes of salinity intrusion in coastal belt of Bangladesh. International Journal of Plant Research, 4(4A), 8-13.

Misstear, B. D., \& Beeson, S. J. H. J. (2000). Using operational data to estimate the reliable yields of water-supply wells. 8(2), 177-187.

Monir, M. U., Khan, Y. A., Hossain, H. Z., \& Hossain, Q. H. (2011). Investigation of Water Quality in the Ganges River, Bangladesh: Implications for Drinking and Household Purposes. International Journal of Economic and Environment Geology, 2(2), 22-24.

Monir, M. U., Khan, Y. A., Quamruzzaman, C., Kabir, A. F., \& Hossain, B. R. (2012). Ganges river water suitability for drinking and household purposes in Rajshahi city area, Bangladesh.

Naggar, O. M. (2005). Optimum design and construction of water wells (case study). Paper presented at the 9th International Water Technology Conference. IWTC9.

Nahin, K. T. K., Basak, R., Alam, R. J. E. S., \& Environment. (2019). Groundwater Vulnerability Assessment with DRASTIC Index Method in the Salinity-Affected Southwest Coastal Region of Bangladesh: A Case Study in Bagerhat Sadar, Fakirhat and Rampal. 1-13. 
Ophey, M. J., Bosch, K., Khalfallah, F. Z., Wijnands, A. M. M. P., van den Berg, R. B., Bernards, N. T. M., . . . Tak, I. J. R. (2019). The decline step-down test measuring the maximum pain-free flexion angle: A reliable and valid performance test in patients with patellofemoral pain. Physical Therapy in Sport, 36, 43-50. doi:https://doi.org/10.1016/j.ptsp.2018.12.007

Rahman, M., Rahman, S. H., \& Majumder, R. K. J. S. J. S. T. (2012). Groundwater quality for irrigation of deep aquifer in southwestern zone of Bangladesh. 34(3), 345-352.

Rajmohan, N., \& Elango, L. J. E. G. (2004). Identification and evolution of hydrogeochemical processes in the groundwater environment in an area of the Palar and Cheyyar River Basins, Southern India. 46(1), $47-61$.

Razack, M., \& Huntley, D. J. G. (1991). Assessing transmissivity from specific capacity in a large and heterogeneous alluvial aquifer. 29(6), 856-861.

Rorabaugh, M. I. (1953). Graphical and theoretical analysis of step-drawdown test of artesian well. Paper presented at the Proceedings of the American Society of Civil Engineers.

Sarker, M. M. R., Van Camp, M., Islam, M., Ahmed, N., \& Walraevens, K. (2018). Hydrochemistry in coastal aquifer of southwest Bangladesh: origin of salinity. Environmental Earth Sciences, 77(2), 39.

Sawant, R., \& Shete, G. (2016). A Review of Early Historic Urbanization in India. A Companion to South Asia in the Past, 319-331.

Shammi, M., Karmakar, B., Rahman, M. M., Islam, M. S., Rahman, R., \& Uddin, M. (2016). Assessment of salinity hazard of irrigation water quality in monsoon season of Batiaghata Upazila, Khulna District, Bangladesh and adaptation strategies.

Shammi, M., Rahman, M. M., Islam, M. A., Bodrud-Doza, M., Zahid, A., Akter, Y., . . . research, p. (2017). Spatio-temporal assessment and trend analysis of surface water salinity in the coastal region of Bangladesh. 24(16), 14273-14290.

Singh, S. K. J. J. o. H. E. (2002). Well loss estimation: Variable pumping replacing step drawdown test. 128(3), 343-348.

Smith, E. J. S., Water Research Foundation of Australia, Report. (1966). Screen Bore Construction. (24).

Tanvir Rahman, M. A., Rahman, S. H., Majumder, R. K. J. S. J. o. S., \& Technology. (2012). Groundwater quality for irrigation of deep aquifer in southwestern zone of Banglades. 34(3).

Walton, W. C. J. B. n. (1962). Selected analytical methods for well and aquifer evaluation.

Zakaria, M., Islam, M., Rahman, M. M. J. I. J. o. A. G., \& Vol, G. (2015). Developing Conceptual Aquifer Geometry, Structural Geological Control and Possibility of Sea Water Intrusion in Cox's Bazar Area of Bangladesh. 3, 21-28.

\section{Hosted file}

Tables .docx available at https://authorea.com/users/315082/articles/445438-hydrostratigraphiccharacterization-in-south-eastern-coastal-aquifer-of-bangladesh-using-lithological-data-andstep-drawdown-test

\section{Hosted file}

Figures . docx available at https://authorea.com/users/315082/articles/445438-hydrostratigraphiccharacterization-in-south-eastern-coastal-aquifer-of-bangladesh-using-lithological-data-andstep-drawdown-test 